\title{
Active Doings and the Principle of the Causal Closure of the Physical World
}

\author{
Ansgar Beckermann*
}

Received: 13 July 2018 / Accepted: 4 December 2018

Abstract: Some philosophers hold that it would be impossible for us to do something actively if the physical world were causally closed, i.e., if in the physical world all events were caused by other physical events if they are caused at all. The reason for this view is that these philosophers adhere to what I call the traditional picture of action. Recently, Martine Nida-Rümelin tried to defend this picture by phenomenological considerations. According to the traditional picture a behavior can only count as something an agent does actively if it is ultimately caused by the agent in an agent-causal way. In this paper I adduce three arguments against agent causation: (1) We do not really understand what agent causation is. (2) If agent causation were real, we would be confronted with the strange fact that human agents can only cause certain tiny events in the brain. (3) There is no empirical evidence that agent causation is real. In the last part of my paper I present an alternative account of the difference between what agents do actively and what is done to them.

Keywords: Active doings; agent causation; causal closure of the physical world; free will; Martine Nida-Rümelin; subject causation.

* Bielefeld University

Department of Philosophy, Bielefeld University, Postfach 1001 31, D-33501 Bielefeld, Germany

$\bowtie$ ansgar.beckermann@uni-bielefeld.de

(C) The Author. Journal compilation (c) The Editorial Board, Organon F.

This article is distributed under the terms of the Creative Commons Attribution-NonCommercial 4.0 International Public License (CC BY-NC 4.0). 


\section{Kant's dilemma}

According to Onora O'Neill, Kant held that we have to adopt two standpoints in leading our lives - standpoints which we cannot help to adopt despite their apparent incompatibility. ${ }^{1}$ On the one hand, there is the theoretical standpoint which is naturalistic, "from it we see the world and human life as subject to natural law and causal inquiry" (O'Neill 1997, 273). On the other hand, there is the practical standpoint, the standpoint of human freedom, "from it we see ourselves as agents who intervene in limited ways in that natural order. Only the theoretical standpoint can accommodate science; only the practical standpoint can accommodate morality" (O’Neill 1997, 273). Moreover, in acting we are often guided by reasonsand reasons are, as many believe, totally different from causes which govern the natural world.

But although we cannot go without any of those two standpoints, it is unclear how they can be true at the same time.

The predicament in which we find ourselves is not that of having to lead our lives in two distinct ontological orders, but that of having to adopt two mutually irreducible standpoints in leading our lives. [...] We are unavoidably, deeply, and thoroughly committed both to the naturalistic standpoint and to the standpoint of freedom. We can dispense with neither standpoint, since neither makes sense without the other. If we do not see ourselves as free we can give no account of activity, hence none of the activities of judging and understanding by which we establish the claims of knowledge; if we do not see ourselves as parts of a causally ordered world we can give no account of the effective implementation of human projects, including moral action, in the world. Our lives would be impossible without commitment to freedom and to causality in the robust sense in which Kant understands these terms: neither can stand alone. Yet we do not understand, let alone know, what makes them compatible. (O’Neill 1997, 272f.)

1 Cf. (Beckermann 2016) concerning this paragraph and the following one. 
I cannot judge to what extent this assessment does justice to Kant's philosophy. However, it seems to me that it captures quite aptly the basic controversy of the German debate on the problem of free will that has taken place in the last decades [cf., for example, (Geyer 2004)]. On the one hand, many scientists insist that the natural sciences tell us that the physical world is a causal net of physical events, which, if they have any causes at all, are caused by other physical events. In this net, therefore, there does not seem to be any room for the intervention of personal agents. On the other hand, many philosophers underscore the indispensability of the practical standpoint. For, so the argument goes, first, daily experience confirms this standpoint a hundred times a day and, second, we cannot but view ourselves and our fellow humans as acting persons; even natural scientists have to understand themselves as acting persons, or else they would undermine the very foundations of their work. And, of course, in particular scientists need to act on the assumption that what they do is guided by reasons. Science is simply defined as the search for those hypotheses that are justified by the best reasons [see (Janich 2008), (Heidelberger 2005)]. To put it in a nutshell, a central claim of the theoretical standpoint is that the physical world is causally closed, that in the physical world, all events, including all movements of the limbs of animals, are caused by other physical events if they are caused at all. A central claim of the practical standpoint in contrast is that some animals and we humans are at least sometimes able to do something actively, we are able to intervene in the course of physical events.

Many scientists and philosophers agree on that the two claims are mutually exclusive. If the theoretical standpoint is true, then the practical one cannot obtain, and if the practical one obtains, then it is impossible at least that the natural sciences yield a complete picture of the world. To some, this incompatibility is so obvious that they wonder how one can even try to overcome it. This, in turn, is due to the fact that they construe especially the practical standpoint in such a way that it is indeed precluded that this standpoint obtains if the theoretical one is true. I call this interpretation "the traditional picture of active doings."

When someone does something actively, this usually means that she intervenes in the course of the physical world. Had she done nothing, this 
world would have developed in a certain way; by her action, however, the course of the physical world changed. Therefore, the idea of active doings seems to imply that, on the one hand, there is the physical world, which, left alone, develops in a certain way. On the other hand, there is the agent, who is somehow located beside or outside this world. She can observe the course of the physical world in a way that does not change anything, ${ }^{2}$ but she can also, within the limits of her possibilities, intervene by action and change the direction of the course of the physical world. It is crucial to see that, according to the traditional picture, doing something actively means to intervene in the course of the physical world from outside. As I see it, in the history of occidental philosophy this basic idea has been spelled out in two different ways - in Cartesian dualism and in the idea of agent causation. Sometimes, these two perspectives are even merged. Both, interactive Cartesian dualism and the idea of agent causation are incompatible with the claim that the physical world is causally closed. If some movements of my limbs are caused by mental events in the sense of Cartesian dualism then some physical events have nonphysical causes. And if some movements of my limbs are caused by me in the sense of agent causation it is certainly not true that these movements have only physical events as causes.

\section{Martine Nida-Rümelin on active doings}

Ten years ago, Martine Nida-Rümelin offered a view of active doings which combines Cartesian dualism with the idea of agent causation. She argues that to say that an animal or a human being is doing something actively is to say that something immaterial caused bodily movements of the animal or the human being in an agent-causal way. Martine NidaRümelin develops her considerations against a phenomenological background - based on an analysis of what we experience when we are active or what we experience when we observe, for example, animals that are actively doing something, instead of suffering something that merely happens to them. Think of a squirrel which runs around and gathers nuts, which climbs

2 Provided the assumption that observation alone does not already change the world. 
a tree and hops from branch to branch. Most people certainly hold that the squirrel has experiences and that it perceives the world in a certain way. According to Nida-Rümelin, however, most people do not only believe this, "[they] perceive it as such" (Nida-Rümelin 2007, 257; emphasis in the original). But, following Nida-Rümelin, to view animals as subjects of experiences implies much more:

But the experience of an animal as a subject of experience normally not only involves being aware of the fact that there is 'someone' who has experiences, it also normally involves awareness of something we might call spontaneity. Seeing, for example, a squirrel as a subject of experience involves, in addition to seeing it as having experiences, seeing it as being active. Seeing a squirrel as a subject of experience involves seeing a great part of its bodily moves as genuine activities. A squirrel's jump from one branch to another does not look to someone who sees the squirrel as a subject of experience like the mere result of some inner mechanical process. It looks like something done by the squirrel, by the subject at issue itself. (Nida-Rümelin 2007, 257)

This similarly applies to the experiences we have when we ourselves do something actively:

An analogous claim applies to the way we perceive ourselves in our own doings. In doing something we are at least normally phenomenally aware of doing something. To be phenomenally aware of doing something involves the experience of oneself as being active. In doing something we experience our own spontaneity. We are aware of the difference between those cases where something merely happens to us and those cases where we directly bring about what happens. (Nida-Rümelin 2007, 258)

Nida-Rümelin's phenomenological thesis therefore is:

[I]t is normally part of the content of our experience when we do something that we are active in that doing; and it is part of the content of our perceptual experience when we observe others in their doings that they are active in what they do. (Nida-Rümelin 2007, 258) 
However, this is not decisive. What is crucial is the transition from a phenomenological to the ontological thesis:

It seems quite obvious to me that to experience oneself as active in one's doing can be described equally well by saying that we experience ourselves as the cause or a cause of what happens. The same applies to the perception of others: to see another animal as being active in its doing is to see it (the other experiencing subject) as a causal origin of its moves. But what is required for the experience to be veridical? Do we need to assume that these experiences can be veridical only if the subject is itself a cause in a sense similar to the one discussed under the heading 'agent causation'? It seems quite clear to me that we have to admit this further step. (Nida-Rümelin 2007, 262; emphasis in the original)

Thus, "to be active," according to Nida-Rümelin, means "to cause something." A being is active only in case it itself causes the bodily movements that constitute its behavior - in the sense of subject causation. NidaRümelin prefers the term "subject causation" to the term "agent causation," because she is concerned not only with actions, but with all activities of which it can be said that humans or other living beings do them on their own (so her concern is for all "active doings").

In this paper I will be primarily concerned with doings or activities rather than with the more specific case of actions. Many things we do in our daily lives are not actions. A person caught in her thoughts might smile, scratch her head, stand up and walk around. Under normal circumstances these activities are not actions, they are only doings. Doings are often done without reason. The author of a doing need not notice what she is doing. Most bodily movements of human and non-human animals while awake are doings. Doings need not be controlled: the spontaneous laughter after hearing a joke, the crying of a baby that longs for the presence of a parent, or the happy smile of surprise when meeting a friend unexpectedly are examples of doings without control. Nonetheless the person is active in her laughing, crying, or smiling. (Nida-Rümelin 2007, 245f.) 
Thus, Martine Nida-Rümelin is concerned not only with actions but with everything that can be considered an active doing. Let us return to the issue of subject or agent causation. ${ }^{3}$ Nida-Rümelin asks whether it makes sense to assume that the subject or the agent causing a behavior is a material being.

Can the claim of subject causation be combined with the idea that the subject of experience is a material thing (the whole body, the brain or a part of the brain)? [...] Suppose that subjects cause events in their brain and that subjects are identical to their brain. It follows that the brain as a whole causes events happing within the brain. (Nida-Rümelin 2007, 264; emphasis in the original)

Is this a reasonable idea? What is it supposed to mean that a physical system causes a process within that system? Does it, for example, make sense to say that a computer causes processes that run within it? "It seems plain that to talk in this way is to talk nonsense. All causation happening in the case of a computer is event causation" (Nida-Rümelin 2007, 264). According to Nida-Rümelin, our brains are not different in this respect. Even if we concede that brains are subjects of experiences, the following applies here as well:

A philosopher who accepts that material objects as a whole can cause events happening inside of them should have a way to render this supposed causal relation conceivable which is independent of the assumption that the object belongs to the special class of experiencing subjects and which is applicable to nonconscious material things as well. If this reasoning is correct then we are confined to a dualist subject causation theory. (Nida-Rümelin 2007, 264)

Nida-Rümelin does not seek to set out a traditional dualism, but that does not matter here. What is important is that she holds that to do something actively means that the subject causes the corresponding physical movements in the sense of agent causation and that the causing subject itself cannot be anything physical, neither a body nor a physical part of a body.

3 In the following I will make no difference between subject and agent causation. 


\section{Objections to agent causation}

I think that Nida-Rümelin is surely right in assuming that there is a difference between what some beings do actively and what only happens to them, what they suffer passively. However, I object to her equating being active with the agent being the cause of bodily movements, in the sense of agent causation without much ado. First, I think, she is wrong about the phenomenology. At least, when I observe a squirrel jumping from branch to branch I do not at all have the phenomenological impression that the squirrel's movements are caused by the squirrel itself or that they are not "the mere result of some inner mechanical process." But what is more important is that Nida-Rümelin so easily pushes aside the many problems that come with the idea of agent causation. In the following I shall raise essentially three objections against agent causation.

A common objection to agent causation has been that it cannot explain the exact time at which the caused event takes place. To me, however, a more general objection, my first objection, seems even more severe. The very notion of agent causation is hardly intelligible. According to the generally acknowledged view, causality involves two relata - cause and effect. In the case of event causation both relata are events. The stone's hitting the glass pane (cause $C$ ) brings about the breaking of the pane (effect $E$ ). With agent causation, however, things are different. There is only one event-the effect $E$. The cause is not an event, but an agent $A$. Agent causation consists, so we are told, in the agent $A$ bringing about the event $E$-straightforwardly, without doing anything else that is the real cause $E$. Of course, I can scare away a fly by moving my hand; but this is just a case of event causation - the movement of my hand causes the fly's disappearance. But the movement of my hand, the exponents of agent causation reply, is not caused by another event, it is caused solely by me. I do not do anything else which causes my hand to move. One central problem that arises from this assumption can be illustrated as follows. In the case of event causation one must answer the question: what distinguishes the case that event $E$ merely followed event $C$ from the case that $C$ indeed caused $E$. This is the question of what constitutes the difference between post hoc and propter hoc. The answer to this question is contentious. Many would, 
however, agree with the following two claims. (a) If $C$ causes $E$, there must be a nomological connection between $C$ and $E$ based on appropriate natural laws. And (b) if $C$ causes $E, E$ would not have occurred if $C$ had not taken place. $^{4}$

What now of agent causation? Here the question is what distinguishes the case that $E$ occurs simply in the presence of $A$ from the case that A causally brings about $E$. To my knowledge, there is not even a remotely satisfactory answer to this question. Often it is said that in the latter case $A$ just caused $E$; however, this is, of course, not an answer, but merely a repetition of the thesis. Therefore, it is all but surprising that traditionally movements caused by an agent are traced back to acts of will; in my view, this is an attempt to model agent causation in analogy to event causation. Still, the question remains what causes those acts of will.

One can also give these questions an epistemic twist. In the case of event causation, the question then is how can I find out whether event $E$ merely follows $C$ or whether $E$ was caused by $C$. In the case of agent causation, the question is how can I find out whether $E$ merely occurred in the presence of $A$ or whether $E$ was caused by $A$. Again, there is, to my knowledge, no satisfying answer to the second question. The only possibility seems to be to ask $A$. But this is not possible with beings incapable of language. Moreover: is information given by agents truly reliable? There is, however, an answer to the first question - by means of experiments. In many experiments researchers try to hold one factor constant - e.g., $C$ - and to systematically vary as many other factors as possible. If in all of these variations $E$ always follows $C$, then this indicates that $C$ caused $E$. This approach is based on the fact that we can actively intervene in the course of the world; because this allows us to isolate the factors with which we can reliably bring $E$ to the fore. Bring to the fore is a decisive term here. If we can reliably make sure that $E$ occurs, by making sure that $C$ occurs, this indicates that $C$ causes $E$. With respect to agent causation, there are then again only open questions. To the best of my knowledge, there is no approach with which we can test whether an agent $A$ has caused an event $E$.

4 Both points are already present in (Hume 1993, Section vii, part ii). 
A second objection is not so fundamental, but should give proponents of the idea of agent causation something to think about. Already Descartes was aware of the fact that the soul cannot directly cause changes in the periphery of our body and that, reversely, things in our environment or states of affairs of our feet and hands cannot directly cause changes in the soul. As soon as the afferent nerves leading from the hand to the brain are interrupted, we no longer feel any more pain from our injured hand; and as soon as the efferent nerves leading from the brain to the hand are interrupted, we can no longer move our hand. The spot of interaction must hence lie in the brain, which for Descartes meant in the pineal gland. Even proponents of agent causation concede that, in general, agents - human beings or animals - can only cause changes in the brain. This leads first and foremost to the question why we do not experience precisely this. When I lift my arm, I may have the experience of causing the lifting of the arm, but certainly not the experience of causing a certain process in my brain. But putting that aside: If it is true that agents can only cause changes in their brains, why is that so? In principle, it should not be more difficult to directly cause certain muscle contractions than to make certain motor neurons fire. And why can't agents directly cause changes in the world, in the way telekinesis is supposed to work? Why do I have to hit the keyboard with my fingers? If there is agent causation, it should be no problem to operate the keys by causing their movements directly. The fact that I cannot do all these things is in my view evidence for the conclusion that something is basically wrong with the idea of agent causation.

A third objection is for those who are not yet convinced by the arguments presented so far. Even if the idea of agent causation were not faced with the problems just mentioned, there is no empirical evidence for the occurrence of such causation. First of all, I already mentioned that agent causation is incompatible with the thesis of the causal closure of the physical world, i.e., the thesis that all events have physical events as causes, if they have any cause at all. Therefore, if agent causation really does occur in this world, two conditions have to be met: 1 . There are physical events which have no (sufficient) physical causes. 2. It can be made plausible that these events are nevertheless caused, namely, by certain agents. Is that feasible? Perhaps. Let us again consider the phenomenon of telekinesis. Suppose 
a person is asked to make a bottle, standing five meters away from her on a table, fall over by "mere power of thinking." Let us suppose further that the person succeeds in eight of ten attempts and that with later repetitions the success rate is approximately the same. This certainly would be a convincing result. I assume that the scientists who conducted the experiment have checked the experimental arrangement carefully. There are no hints with respect to manipulation or technical tricks of any kind. In other words: There is no evidence of physical causes for the bottle's tilting over. Apparently, it is the subject alone who succeeds by mere power of thinking or willing to make the bottle fall over. This is possible; but, actually there is no empirical evidence for such cases. Here and there we find scattered reports of the kind in question, but telekinetic phenomena could so far not be proved in systematic examinations.

In this context, ever since Descartes, interactionistic dualists have applied a remarkable trick. They assume that the physical effects that can be brought about by the soul or by agents are very small and therefore hardly observable. Descartes, for example, held that the soul cannot do more than cause certain movements (twists) of the pineal gland. ${ }^{5}$ But even if this were the case: The interaction of the soul with the physical world would have to be demonstrated by first ascertaining that certain movements of the pineal gland have no sufficient physical causes and secondly, by making plausible that those movements nevertheless have a cause - the soul.

Nowadays, obviously there are only few proponents of agent causation (if any) who explicate in detail which brain events agents can cause. The firing of motor neurons, however, as well as the firing of other neurons is essentially dependent on which and how many neurotransmitters are being released from the synaptic terminals of precedent neurons. Hence, those

5 John Ecces holds that the mind can only interact with a certain part of the cortex (the liaison brain). The mind scans small functional units (modules) in that area which are accessible to it due to their "openness" and "slightly modifies them, whereupon the modules react collectively to these slight alterations and forward this common reaction via the associational and commissural fibres" (Eccles and Zeier 1980, 173; my translation). In his more recent work, Eccles conjectures the location of the mind/matter-interaction in dendrones, units even smaller than the modules. 
authors have to assert something like the following: In some cases, the release of neurotransmitters (1) has no sufficient physical cause, but (2) it has, as can be made plausible, nevertheless a cause - the agent herself. Or, to take another example: In some cases, the generation of an action potential in a motor neuron (1) has no sufficient physical cause, but (2) it has, as can be made plausible, nevertheless a cause - the agent herself. Undoubtedly, it is far from easy to examine such assertions empirically. However, to my knowledge we don't yet have the slightest evidence speaking in favor of the truth of those claims.

\section{A naturalistic alternative}

I agree that there is indeed a difference between active and passive. With regard to the movements of a human being, we can justifiably claim that some of these movements are due to the person herself - she lifts her arm; she sings a song; she scratches her head. On the other hand, there also are movements which are not doings of the person-somebody takes my arm and pulls it up; someone pokes me to the ground. In both cases, these movements of my arm or my body cannot be ascribed to myself. In my view, however, it inevitably leads to a dead end if one tries to spell out the difference between active and passive by means of the idea of agent causation. But what could an alternative account look like?

To begin with, at least one fundamental difference between actively moving and passively being-moved is that the latter is often brought about by external forces. ${ }^{6}$ A blast of wind blows me over, Fido the dog is pulled away from his favorite tree - in both cases, external forces affect me and Fido, respectively, causally bringing about the corresponding movements. It is something altogether different if Fido gets up from his basket and runs to the door. Of course, this too can have (amongst others) external causes, e.g., the noise being caused by the unlocking of the door. But this cause works in a completely different way than the blast of wind or the dog's master pulling the leash. Fido's running consists in the movement of his

\footnotetext{
6 Cf. (Beckermann 2008, § 2.3) and (Beckermann 2011) with respect to this paragraph and the following ones.
} 
legs, but the noise at the door doesn't exert any forces on those legs. In fact, the movement of Fido's legs is based solely on the contraction and relaxation of certain muscles. External forces do not play any role here. That animals move by themselves thus means at least in part that the energy which is necessary for the execution of such movements stems from within them.

However, this aspect alone does not suffice. Consider the patellar reflex.

Striking the patellar ligament with a reflex hammer just below the patella stretches the muscle spindle in the quadriceps muscle. This produces a signal which travels back to the spinal cord and synapses (without interneurons) at the level of L3 in the spinal cord, completely independent of higher centres. From there, an alpha motor neuron conducts an efferent impulse back to the quadriceps femoris muscle, triggering contraction. This [...] causes the leg to kick. (<https://en.wikipedia.org/wiki/Patellar_reflex>)

In this case, too, no external forces affect the leg; the energy needed for its movement stems completely from the patient himself. Still, in this case we don't say that the person herself has lifted her leg. In general, the following applies: Internally induced movements of a person's limbs rest on muscle contractions and relaxations. Those contractions and relaxations are themselves brought about by the firing of motor neurons whose cell bodies are located in the anterior horn of the spinal cord and whose axons reach down to neuromuscular endplates directly neighboring muscle cells. The lower motor neurons can in turn be activated by upper motor neurons, the cell bodies of which lie in the motor cortex of the brain and axons of which reach to the cell bodies of the lower motor neurons located in the anterior horn.

With regard to the kicking of the leg due to the patellar reflex, no higher regions of the CNS are involved. This is important. For in the neurobiological literature one can often read that it is the upper motor neurons which are responsible for intentional movements. In other words: With regard to intentional movements, the neuronal impulse leading to the corresponding contractions and relaxations must come from the motor cortex. This suggests the 
following way to characterize active doings: A human being moves one of his limbs actively if the corresponding muscle contractions trace back to neuronal impulses from his motor cortex. But that is still not the whole story.

With regard to human beings, there is an option we don't have concerning animals - we can ask them whether they did something by themselves, i.e., whether they ascribe a certain movement of their limbs to themselves or to outward causes. This was taken advantage of by Roger Penfield, who during surgeries on open brains in the middle of the $20^{\text {th }}$ century induced complete movements of limbs by stimulating the premotor cortex and supplementary motor area. However, as Gerhard Roth reports in his book Fühlen, Denken, Handeln, the patients experienced these movements as imposed; they did not say: "I did that." 7,8 Thus the fact that the neuronal impulse that led to a movement of a limb originated from the motor cortex of a person does not suffice to his ascribing the move to himself. Rather, it seems that this is only the case if the impulse came about in a specific way. In the first edition of the book mentioned, Roth presented the following hypothesis:

The impression of our movements being instigated by ourselves in an act of will rests on a completely different reason. This impression is a sign for our brain that before the movement started the dorsal and ventral cortico-limbic loop has been passed through and that the executive centers of the cerebral cortex together with the limbic system have 'sufficiently dealt' with it. In this case the symmetric and then the lateralized readiness potential build up, and the latter makes the 'starting shot' for the execution of the

7 German original: "Ich habe das getan".

8 Cf. (Roth 2003, 515). On the other hand, Roth refers to José Delgado who "reported that under conditions similar to those of Penfield, the stimulation of the rostral part of the so-called internal capsule (i.e., the fibers that run from the thalamus through the basal ganglia to the cortex) led to movements of the patient which he ascribed to himself" (Roth 2003, 516; my translation). In (2009), Winfried Löffler conducted a critical and to my mind convincing analysis of Roth's description of Delgado's findings. Löffler's conclusion: There are so far no empiricial findings that suggest it is possible to externally stimulate real actions (actions that agents ascribe to themselves "in the truest phenomenological sense"). 
intended movement. The impression of fiat!, of I want this now is therefore the conscious notification of this neurophysiological process. (Roth 2001, 446; my translation) ${ }^{9}$

In the second edition of his book, Roth did not repeat this hypothesis. Perhaps, however, the exact details are not decisive. Maybe it is enough to notice that people seem to ascribe just those movements to themselves which rest on neuronal impulses from the motor cortex that in turn have been neuronally produced in a certain way.

At any rate, these findings fit in very well with the following idea: $\mathrm{Hu}-$ mans (and some animals) are in a certain way automata - entities that move by themselves; but they are not automata that always act mechanically, knee-jerk or thoughtlessly, i.e., automatically. Rather they are autonomous systems. Firstly, this means that they have a repertoire of diverse behavioral patterns which allows them to act differently even in situations of the same kind. And, second, it means that they have the ability to choose between those different behaviors according to the situation. This ability contains two sub-capabilities - the ability to analyze the situation at hand appropriately (Which objects are where in relation to me? Are those objects dangerous or useful? etc.) and second, the ability to find a course of action which in the given situation serves the attainment of one's own goals. A dog is being attacked; it needs to choose between fight and flight. This decision rests, if I see this correctly, on a neuronal decision-making process. The dog itself (or maybe even the dog's self) plays no role in the causation of the dog's behavior.

In other words: Humans (and many animals) have a decision-making or control system that allows them to find their way in very diverse situations

9 German original: "Das Gefühl der Selbstveranlassung unserer Bewegungen im Willensakt haben wir aus einem ganz anderen Grund. Dieses Gefühl ist für das Gehirn ein Zeichen, dass vor dem Starten der Bewegung die dorsale und ventrale cortical-limbische Schleife durchlaufen wurde und die exekutiven Zentren der Großhirnrinde zusammen mit dem limbischen System sich damit 'ausreichend befasst' haben. In diesem Falle baut sich das symmetrische und dann das lateralisierte Bereitschaftspotential auf, und letzteres gibt den 'Startschuss' für die Ausführung der intendierten Bewegung. Das Gefühl des fiat!, des ich will das jetzt ist demnach die bewusste Meldung dieses neurophysiologischen Vorgangs."

Organon F 26 (1) 2019: 122-140 
and to choose the course of action that seems most beneficial. This control system is, from what we know, realized in the CNS. Therefore, my hypothesis is that the neuronal subsystems of the CNS, which play a central role in Roth's considerations, are precisely those parts of the brain in which the control system is realized that makes us autonomous systems. That is to say, humans and animals carry out those movements themselves that are based on neuronal impulses from those parts of the motor cortex that are in turn under the control of their central neuronal control system.

However, one restriction must be added: perhaps it is possible to induce movements by stimulating certain cerebral regions, which the respective persons then ascribe to themselves. ${ }^{10}$ In this case, one would have to say that these persons were wrong. In fact, these movements were none of their doings. Therefore, one should finally say: humans and animals carry out those movements themselves that are based on neuronal impulses from the motor cortex, which in turn are being controlled by their central neuronal control system, as long as this control system is not manipulated from outside, i.e., as long as the humans and animals are not being "remote-controlled." This point is very important, too. Remote-controlled model airplanes or toy robots resemble animals in many ways. But they don't act on their own as long as they're being controlled from outside. This would be different only if by implementation of internal control-systems the model airplanes or robots became autonomous systems themselves.

\section{Summary}

I think, just like Martine Nida-Rümelin, that there is a real distinction between active and passive, between what humans and other living beings do actively and what merely happens to them. I take it to be a mistake, however, to spell out this difference in terms of agent causation. It is in general a mistake to construe agents as entities beside or outside the physical world. Humans and animals are as much part of the physical world as stones and rivers. They differ from stones and rivers only in that they are

10 Once again: Delgado's findings do not indicate this. But that doesn't mean that it isn't possible. 
much more complex and contain many physical mechanisms which make them autonomous systems - but not in that they contain additional nonphysical components. When they intervene in the course of the physical world, they do so from within, as part of this world.

But is Nida-Rümelin not right in claiming that we often have the phenomenal impression that we as agents cause some of our movements? Here I would like to make three comments. First, phenomenal impressions may be wrong. I approach the door of a supermarket and the door opens. I may have the impression that my approaching the door was the cause of the opening of the door. But I may be wrong; the opening of the door may have quite another cause. Second, is it really true that I often have the phenomenal impression that I as an agent cause some of my movements? I doubt that. I agree that I often have the phenomenal impression that one of my movements is something I do actively, not something that happens to me. But in my view this impression is not directly about causation. Remember how Nida-Rümelin initially expresses herself:

To be phenomenally aware of doing something involves the experience of oneself as being active. In doing something we experience our own spontaneity. (Nida-Rümelin 2007, 258)

Initially she does not say that in doing something actively we experience ourselves as causing our behavior. Third, scientific progress sometimes forces us to adjust our phenomenal experiences or at least to interpret them in a new way. I have the phenomenal impression that the table in front of me is a solid object, i.e., that the space it covers is entirely filled with a hardly penetrable material. But science tells us that the table is made up of billions of atoms at a large distance from each other and that there is plenty of empty space between the atoms. Nonetheless, our phenomenal impression that the table is solid can be saved, since other solid objects like a cup that I put on the table will not fall through it. The reason is that the forces holding together the atoms of the table and the cup respectively are so big that the atoms cannot easily be separated from each other. In much the same way the problems with which the idea of agent causation is confronted and the fact that scientists have found no evidence whatsoever that agent causation is real should motivate us to interpret doing something actively in a way that does not depend on the idea of agent causation. 
I have tried to sketch such an alternative account. Besides the fact that this account of active doings avoids the problems of the idea of agent causation, it has another advantage. It demonstrates that doing something actively is compatible with the principle of the causal closure of the physical world. If a behavior is an active doing in fact it is caused by a very specific kind of neuronal processes then even active doings may have only physical events as causes. Thereby, the analysis also opens up a solution of the Kantian dilemma. We can very well understand ourselves simultaneously as part of the physical world which is causally closed and as active beings. ${ }^{11}$

\section{References}

Beckermann, Ansgar. 2008. Gehirn, Ich, Freiheit. Neurowissenschaften und Menschenbild. Paderborn: mentis.

Beckermann, Ansgar. 2011. "Ich sehe den blauen Himmel, ich hebe meinen Arm."

In Geist und Moral, edited by Christoph Lumer and Uwe Meyer, 19-34. Paderborn: mentis.

Beckermann, Ansgar. 2016. "Willensfreiheit. Die Agenda des Naturalisten." In

Wollen. Seine Bedeutung, seine Grenzen, edited by Neil Roughley and Julius

Schälike, 341-67. Paderborn: mentis.

Eccles, John C., and Hans Zeier. 1980. Gehirn und Geist. München: Kindler.

Geyer, Christian, ed. 2004. Hirnforschung und Willensfreiheit. Frankfurt am Main:

Suhrkamp.

Janich, Peter. 2008. "Naturwissenschaft vom Menschen versus Philosophie." In

Deutsches Jahrbuch Philosophie Band I: Naturalismus und Menschenbild, edited by Peter Janich, 30-51. Hamburg: Meiner.

https://doi.org/10.1524/dzph.2007.55.6.893

Heidelberger, Michael. 2005. "Freiheit und Wissenschaft! Metaphysische Zumutungen von Verächtern der Willensfreiheit." In Neurowissenschaften und Menschenbild, edited by Eve-Marie Engels and Elisabeth Hildt, 195-219. Paderborn: mentis.

Hume, David. 1993. Untersuchung über den menschlichen Verstand. Übersetzt von R. Richter, mit einer Einleitung herausgegeben von J. Kulenkampff. Hamburg: Meiner.

11 Translated from a German version with the help of Alin Cucu. 
Löffler, Winfried. 2009. "Neuromythologie, oder: Wie aus empirischen Mücken narrative Elefanten werden." In Gehirne und Personen, edited by Martina Fürst, Wolfgang Gombocz, and Christian Hiebaum, 113-26. Frankfurt am Main: Ontos.

Nida-Rümelin, Martine. 2007. "Doings and Subject Causation." Erkenntnis 67 (2): 255-72. https://doi.org/10.1007/s10670-007-9064-z

O'Neill, Onora. 1997. "Kant on Reason and Religion." Tanner Lectures on Human Values 18: 267-308.

Penfield, Wilder. 1958. The Excitable Cortex in Conscious Man. Springfield, Ill.: Liverpool University Press.

Roth, Gerhard. 2001. Fühlen, Denken, Handeln. $1^{\text {nd }}$ ed. Frankfurt am Main: Suhrkamp.

Roth, Gerhard. 2003. Fühlen, Denken, Handeln. Neue, vollständig überarbeitete Ausgabe, $2^{\text {nd }}$ ed. Frankfurt am Main: Suhrkamp. 